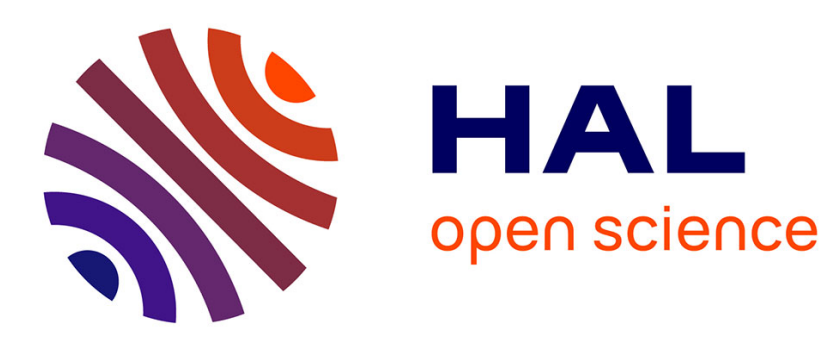

\title{
A Mechanical Model for the Onset of Damage in Rubber Modified Amorphous Polymers
}

\author{
C. Fond, R. Schirrer
}

\section{To cite this version:}

C. Fond, R. Schirrer. A Mechanical Model for the Onset of Damage in Rubber Modified Amorphous Polymers. Journal de Physique IV Proceedings, 1996, 06 (C6), pp.C6-375-C6-384. 10.1051/jp4:1996637 . jpa-00254465

\section{HAL Id: jpa-00254465 https://hal.science/jpa-00254465}

Submitted on 1 Jan 1996

HAL is a multi-disciplinary open access archive for the deposit and dissemination of scientific research documents, whether they are published or not. The documents may come from teaching and research institutions in France or abroad, or from public or private research centers.
L'archive ouverte pluridisciplinaire HAL, est destinée au dépôt et à la diffusion de documents scientifiques de niveau recherche, publiés ou non, émanant des établissements d'enseignement et de recherche français ou étrangers, des laboratoires publics ou privés. 


\title{
A Mechanical Model for the Onset of Damage in Rubber Modified Amorphous Polymers
}

\author{
C. Fond and R. Schirrer \\ Institut Charles Sadron, 6 rue Boussingault, 67083 Strasbourg, France
}

\begin{abstract}
At medium loading rates, void formation usually precedes plasticity in the matrix around the particles in rubber toughened polymers. Many authors have proposed models for the relationship between rubber surface energy, volume strain energy and void growth. In this paper, it is shown that another volume criterion must also be satisfied, arising from the fact that in all these models, no decohesion is allowed at the particle-matrix interface. A fracture mechanics approach, where linear and non linear elasticity are assumed for the matrix and the rubber particle respectively, is used to define a void formation criterion depending on the rubber fracture surface energy. After formation, the stability of the void is examined, taking into account the volume conservation between matrix and particle and the stress due to surface tension when the void size is very small. A size effect is observed, indicating that voids cannot grow in small particles. The required value of fracture energy in a particle on a microscopic scale is discussed.
\end{abstract}

\section{GLOSSARY}

$a_{0}$ radius of the void inside the rubber particle

a radius of the deformed void inside the rubber particle

$\mathrm{E}_{\mathrm{m}}$ Young's modulus of the matrix

$k_{c}$ bulk modulus of the core of the particle

$k_{m}$ bulk modulus of the matrix

$k_{r}$ bulk modulus of the rubber

$\mathrm{ph}$ pressure in the rubber particle before void

ph appearance

$s_{F} \quad$ fracture surface

sint inner void surface (stretched)

$U_{1}$ potential energy outside the particle (external forces

$\mathrm{U}_{1}$ and matrix)

$u^{\gamma}$ elastic shear energy in the particle after void

$U_{2}$ appearance

$\mathrm{U}_{3}$ energy dissipated in void formation

$\mathrm{V}_{\mathrm{pi}}$ volume of the $i^{\text {th }}$ particle

$\Gamma_{F}$ specific surface energy of the rubber

$\mu_{\text {eff }}$ homogenised shear modulus of a blend

$\mu_{p} \quad$ shear modulus of the rubber

$v_{p}$ Poisson's ratio of the rubber particle

$\sigma^{\infty}$ hydrostatic component of the external load applied

$\sigma_{h}$ at infinity

$\sigma_{\theta \theta}$ tangential stress

$\sigma_{y}$ yield stress of the matrix

$\tau_{\mathrm{e}} \quad$ Von Mises equivalent stress

\begin{tabular}{|c|c|}
\hline$b_{0}$ & radius of the rubber particle \\
\hline b & radius of the deformed rubber particle \\
\hline $\mathrm{E}_{\mathbf{p}}$ & Young's modulus of the rubber particle \\
\hline $\begin{array}{l}\mathbf{k}_{\text {eff }} \\
\mathbf{k}_{\mathrm{p}}\end{array}$ & $\begin{array}{l}\text { homogenised bulk modulus of a blend } \\
\text { homogenised bulk modulus of the particle }\end{array}$ \\
\hline Pext & $\begin{array}{l}\text { pressure applied by the matrix on the rubber particle } \\
\text { pressure applied inside the void by surface tension } \\
\text { (if any) }\end{array}$ \\
\hline$s_{i j}^{\infty}$ & $\begin{array}{l}\text { deviatoric components of the external loading } \\
\text { applied at infinity } \\
\text { temperature }\end{array}$ \\
\hline $\mathrm{U}_{2}$ & $\begin{array}{l}\text { elastic energy inside the particle before void } \\
\text { appearance }\end{array}$ \\
\hline $\mathrm{U}_{2}$ & $\begin{array}{l}\text { elastic hydrostatic energy in the particle after the } \\
\text { void appearance }\end{array}$ \\
\hline$v_{p}$ & volume fraction of particles in the matrix \\
\hline $\mathrm{V}_{\mathrm{t}}$ & total volume of particles and matrix \\
\hline $\begin{array}{l}\Gamma_{\mathrm{st}} \\
\mathrm{a}=\mathbf{a} / \mathrm{a}_{\mathrm{o}} \\
\mu_{\mathrm{m}}\end{array}$ & $\begin{array}{l}\text { surface tension of the rubber } \\
\text { extension ratio at the inner void surface } \\
\text { shear modulus of the matrix }\end{array}$ \\
\hline$v_{\mathrm{m}}$ & Poisson's ratio of the matrix \\
\hline$\sigma_{h}$ & hydrostatic component of the stress tensor \\
\hline$\sigma_{\mathrm{ij}}^{\infty}$ & stress tensor applied at infinity \\
\hline$\sigma_{\mathrm{rr}}$ & radial stress \\
\hline$\omega$ & energy density to initiate the appearance of a void \\
\hline
\end{tabular}

\section{INTRODUCTION}

In many polymers toughened by rubber particles, it is known that, at medium loading rates, damage occurs through cavity formation in the particles [1] and subsequent yielding of the matrix around the particles [2]. Yielding occurs after cavity formation owing to the relatively large and instantaneous decrease of the hydrostatic tension stress in a particle where a void is developing. Since the mechanism of the process is 
known, models describing this damage may be discussed. Recent papers [2,3,4] have modelled the formation of a cavity in a rubber particle on the basis of an energy balance criterion. The energies considered both in these models and here involve a surface tension and a debonding energy in the rubber. In [2] the debonding energy corresponds to the stored strain energy at a critical biaxial extension ratio (typically 5) while in [4] this energy corresponds to "a scission of skeletal bonds". As shown later, if a Griffith's scheme is applied (energy conservation), the strain around the void in the particle is not necessarily constant, so that the energies calculated in this paper differ from [2] and agree with [4]. Nevertheless, in [4], the extension ratio of the rubber is not considered. Moreover, the volume change of the particle after void formation calculated in [4] does not take into account the contribution of the matrix, and in [3] the decrease of the hydrostatic strain in the particle to approximately zero is omitted in the calculation of the change of volume.

As will be shown later, the volume created inside the particle is nearly constant to accommodate the volume change after void formation. Indeed, applying only a simple energy balance criterion violates the additional volume criterion due to the fact that no decohesion is supposed to occur at the particle-matrix interface. Herein the equality between the volume of the "hole" in the matrix and the volume of the particle is also taken into account. The proposed energy balance takes into consideration a fracture surface energy and a surface tension energy as well as surface tension forces at small void radius into account. In contrast, the simple volume strain energy indicates only whether or not rupture occurs in the particle and whether or not a new surface is created. The conclusions concerning the influence of the particle size on the onset of cavity development are similar to those of previous analyses $[2,3,4]$. However, the stability of the void, once created, is described by a different criterion: in the initial geometry (no void) the energy balance contains the total energies and in the final geometry (with void), the derivatives of these energies, in which the potential hydrostatic strain energy of the particle has become very low. The change of geometry when a void appears, from a mechanical point of view, induces a discontinuity in the energy functions, whatever the size of the void.

\section{SMALL STRAIN PARTICLE BEHAVIOUR, BEFORE CRACKING}

\section{1. Pure rubber particle}

In the case of an infinite elastic isotropic matrix subjected to a uniaxial tensile stress and containing one ellipsoidal inclusion, the analytical solution of the stress state in the inclusion is given by Eshelby $[5,6]$. The shear stress $\mathrm{s}_{\mathrm{ij}}^{\mathrm{p}}$ in the inclusion is:

$$
s_{\mathrm{ij}}^{\mathrm{p}}=\frac{5 \mu_{\mathrm{p}}}{3 \mu_{\mathrm{m}}+2 \mu_{\mathrm{p}}} \mathbf{s}_{\mathrm{ij}}^{\infty}
$$

where $s_{i j}^{\infty}$ is the deviatoric component of the uniform stress $\sigma_{i j}^{\infty}$ applied at infinity, $\mu_{m}$ is the shear modulus of the matrix and $\mu_{\mathrm{p}}$ the shear modulus of the inclusion. In the present discussion concerning rubber particles in toughened polymers, the subscript " $p$ " will denote properties of the particles and the subscript " $\mathrm{m}$ " properties of the matrix. Since the ratio $\mu_{\mathrm{p}} / \mu_{\mathrm{m}}$ is usually low for rubber particles, $\mathrm{s}_{\mathrm{ij}}^{\mathrm{p}}$ is a second order term and will be neglected. The stress and strain states of the particle may be split into elementary situations (Fig. 1), as in the classical problem of a hole submitted to internal pressure [7,8].

In the presence of a spherical hole in which an hydrostatic pressure $p_{h}$ is applied, the supplementary elastic energy in the matrix (boundary displacement conditions at infinity for instance) is deduced from [5, 6]:

$$
U_{1}=-\frac{v_{p}}{2}\left\{\left[\sum_{i=1}^{3} \sum_{j=1}^{3} s_{i j}^{\infty 2} \frac{15\left(1-v_{m}\right)\left(1+v_{m}\right)}{E_{m}\left(7-5 v_{m}\right)}\right]+\sigma_{h}^{\infty 2} \frac{9\left(1-v_{m}\right)}{2 E_{m}}-p_{h}^{2} \frac{3\left(1+v_{m}\right)}{2 E_{m}}\right\}
$$

where $E_{m}$ is Young's modulus of the matrix, $v_{m}$ is Poisson's ratio of the matrix, $v_{p}$ the volume of the rubber particle, and $\sigma_{\mathrm{h}}^{\infty}$ the hydrostatic component of the stress applied at infinity. The bulk modulus $\mathrm{k}_{\mathrm{m}}$ 
and shear modulus $\mu_{m}$ are obviously deduced from $E_{m}$ and $\nu_{m}$. The elastic energy $U_{2}$ stored in the particle is a function of the hydrostatic volume strain:

$$
\mathrm{U}_{2}=\frac{\mathrm{v}_{\mathrm{p}}}{2} \frac{\mathrm{p}_{\mathrm{h}}^{2}}{\mathrm{k}_{\mathrm{p}}}
$$

Hence the rubber particle reacts to an applied shear stress like a spherical hole and this is expressed by eq. (1). The hydrostatic pressure $\mathrm{p}_{\mathrm{h}}$ in the particle ensures the displacement continuity at the interface, since there is no decohesion at the particle-matrix interface (i. e. change of volume):

$$
\mathrm{p}_{\mathrm{h}}=\frac{\left(1-v_{\mathrm{m}}\right)}{\left(1+v_{\mathrm{m}}\right)} \frac{9 \mathrm{k}_{\mathrm{p}} \sigma_{\mathrm{h}}^{\infty}}{4 \mu_{\mathrm{m}}+3 \mathrm{k}_{\mathrm{p}}}
$$
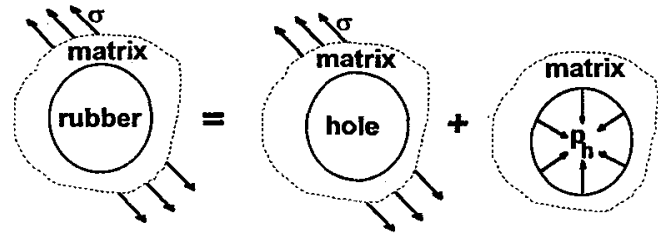

Fig. 1. Elementary situations corresponding to a rubber particle in a matrix subjected to an external load.

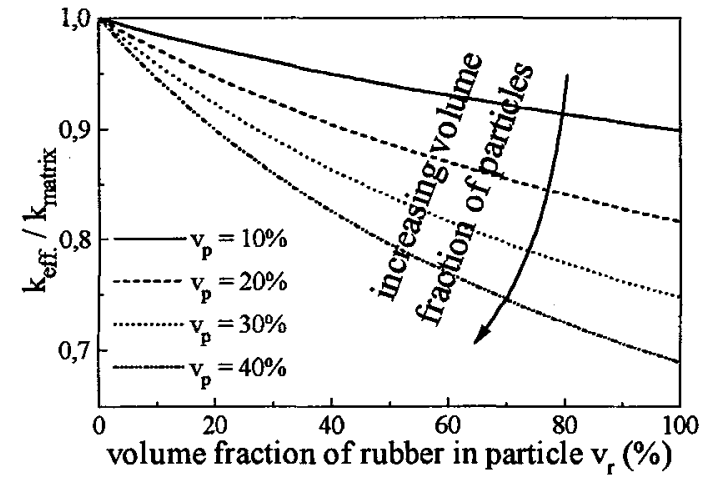

Fig. 2. Calculated mean bulk modulus for R.T. PMMA with core-shell particles (PMMA hard core) with $\mathrm{k}_{\mathrm{m}} / \mu_{\mathrm{m}}=14 / 3$ and $k_{\mathrm{p}} / \mu_{\mathrm{m}}=28 / 15$.

As the model takes the morphology of the blend into account, it can predict both the elastic moduli and the threshold of damage. The elastic moduli are deduced from Eshelby's results for spherical cavities and low particle volume fractions $v_{p}$ (no interactions between particles) [9]. Eq. (2) shows that the effective bulk modulus $\mathrm{k}_{\mathrm{eff}}$ is:

$$
\frac{k_{\text {eff }}}{k_{m}}=\frac{1}{1+\sum_{i=1}^{n} \frac{V_{p i}}{v_{t}} \frac{3\left(1-v_{m}\right)}{2\left(1-2 v_{m}\right)}\left[1-\frac{\left(1+v_{m}\right)}{3\left(1-v_{m}\right)}\left(\frac{p_{h_{i}}}{\sigma_{h}^{\infty}}\right)^{2}\right]}
$$

where $\mathrm{n}$ is the number of particles, $\mathrm{phi}_{\mathrm{hi}}$ the pressure applied at the interface by the $i^{\text {th }}$ particle, $V_{\mathrm{pi}}$ the volume of the $i^{\text {th }}$ particle and $V_{t}$ the total volume. Interactions between rubber particles are known to be important in real rubber toughened polymers [10]. Since the present model does not take these interactions into account, it should not be employed when the particle volume fraction exceeds 5 to $10 \%$ [9]. Although more efficient models (self-consistent) exist to estimate the elastic moduli of such blends, a description of the approach to fracture of the rubber particles requires some simplifications.

\section{2. Core-shell rubber particle}

Using finite element calculations, it can be shown that core-shell (hard core) particles behave like pure rubber particles, and thus like a compressible fluid, even if the thickness of the rubbery shell is less than 5\% of the particle diameter. The mean bulk modulus of one core-shell particle is then:

$$
\mathrm{k}_{\mathrm{p}}=\frac{\mathrm{k}_{\mathrm{c}} \mathrm{k}_{\mathrm{S}}}{\mathrm{k}_{\mathrm{s}}\left(1-\mathrm{v}_{\mathrm{r}}\right)+\mathrm{k}_{\mathrm{c}} \mathrm{v}_{\mathrm{r}}}
$$

where $k_{c}$ is the core modulus, $k_{s}$ the bulk modulus of the shell and $v_{r}$ the volume fraction of rubber in the particle (Fig. 2). 


\section{VOID GROWTH IN PURE RUBBER PARTICLE}

\section{Model for void growth}

\section{1. 1. Nature of the void}

Voids in rubber have already been observed in macroscopic rubbery samples [11], and the expansion of such voids has been largely studied in incompressible materials [8] and used for crack expansion prediction [12]. In the case of particles in toughened polymers, the void is usually supposed to be unique and located at the centre of the particle. The onset of void formation corresponds necessarily to cracking of the rubber and the further stability of the enlarged void is governed by the surface tension $\Gamma_{\text {st }}$ and the fracture energy $\Gamma_{\mathrm{F}}$.

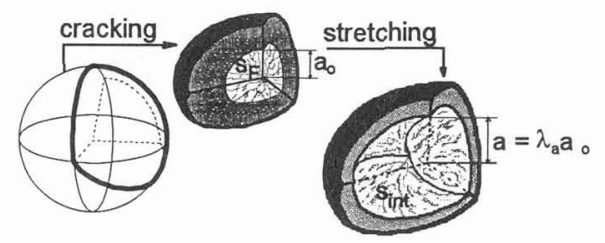

Fig. 3. Schematic fracture surface defined by four planes at $109^{\circ} 5$ in a spherical particle. Three of the four propagation planes are shown here.
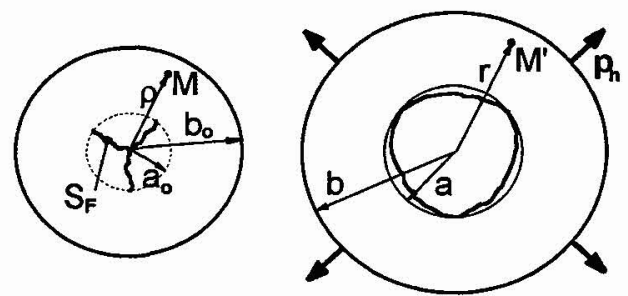

Fig. 4. Schematic representation of void growth by cracking in a rubber particle.

At initial cracking, the voids created are difficult to define in shape. The small size of these voids, close to the molecular level, allows one to argue either from a molecular point of view or from a mechanical point of view. Using a molecular approach, the onset of void formation may be considered to obey a liquid-like flow mechanism within a spherical shape, with a progressive transition to rubbery state behaviour when the void becomes larger. According to a mechanical approach, the void first develop with a more or less complicated closed crack surface and then opens to an approximately spherical shape. In this case, the shape of the closed crack, which is as close as possible to the smallest surface/volume ratio of the subsequent spherical void, is that of four intersecting planes (Fig. 3). The surface created $\mathrm{s}_{\mathrm{F}}$ is very close to the surface of a sphere (Fig. 4):

$$
\mathrm{s}_{\mathrm{F}} \approx 3.65 \pi\left(\mathrm{a}_{\mathrm{o}}^{2}\right) \approx 4 \pi\left(\mathrm{a}_{0}^{2}\right)
$$

where $a_{0}$ is the radius of the void. Hence the energy dissipated $U_{3}$ which stabilizes the void is:

$$
\mathrm{U}_{3}=\Gamma_{\mathrm{st}} \mathrm{s}_{\mathrm{int}}+\Gamma_{\mathrm{F}} \mathrm{s}_{\mathrm{F}}
$$

where $s_{\text {int }}$ is the stretched internal surface of the void. The internal surface created is approximated by (Fig. 4):

$$
\mathrm{s}_{\mathrm{int}} \approx 4 \pi\left(\lambda_{\mathrm{a}} \mathrm{a}_{0}\right)^{2} \quad \text { where } \lambda_{\mathrm{a}}=\frac{\mathrm{a}}{\mathrm{a}_{\mathrm{o}}}
$$

The material within the volume defined by the radius $a_{0}$ or a (Fig. 4), typically less than $1 \%$ of the particle volume, can be neglected for the calculation of stresses and energies. The energy dissipation is here proportional to the surface of the void, as opposed to the notably different result given in a previous paper [2], where this energy is proportional to the volume of the void according to the term $4 \Gamma_{G} \pi \mathrm{a}_{0} 3 / 3$, which corresponds to a particular value of the limiting extension ratio $\left(\lambda_{\mathrm{a}}=5\right)$ of the rubber.

\section{1. 2. Particle volume and hole volume in the matrix}

The radii of the particle before and after deformation are respectively $b_{0}$ and $b$. Since no decohesion occurs at the interface, the radius $b$ also defines the volume of the "hole" in the matrix containing the particle:

$$
b=r_{\left(\rho=b_{0}\right)}=b_{o}\left\{1+\frac{3 \sigma_{h}^{\infty}\left(1-v_{m}\right)}{2 E_{m}}-\frac{\sigma_{m\left(\rho=b_{0}\right)}}{4 \mu_{m}}\right\}
$$


where $r_{\left(\rho=b_{0}\right)}$ is $b$, the radius of the particle after deformation [9], $\sigma_{m\left(\rho=b_{0}\right)}$ is the radial pressure at the interface as given by eq. (11) and $\rho$ is the radius of the particle before deformation.

\section{2. Stresses and energies in the stretched particle}

Values of the radial stress $\sigma_{\pi \mathrm{r}}$ and tangential stress $\sigma_{\theta \theta}$ derived from the of rubber-like elasticity theory $[8,1]$ for incompressible rubber may be used to calculate the stress field, although the strain $\lambda$ at $a_{0}$ must be slightly corrected to take into account the strain owing to compressibility [9]. The radial stress $\sigma_{\mathrm{rr}}$ at the interface is:

$$
\sigma_{\mathrm{rr}}=p_{\text {int }}+\frac{\mu_{\mathrm{p}}}{2}\left(4 \mathrm{~A}^{\frac{-1}{3}}+\mathrm{A}^{\frac{-4}{3}}-4 \lambda_{\mathrm{a}}^{-1}-\lambda_{\mathrm{a}}^{-4}\right) \quad \text { where } \quad \mathrm{p}_{\mathrm{int}}=\frac{2 \Gamma_{\mathrm{st}}}{\mathrm{a}}
$$

$A=1+\left(\lambda_{a}{ }^{3}-1\right)\left(\frac{a_{0}}{b_{o}}\right)^{3}$ and $p_{\text {int }}$ is the internal loading due to surface tension (Van Der Waals attractions). Clearly, $\lambda_{\mathrm{a}}$ becomes greater than 1 when the particle breaks. The predicted radial pressure $\left(\sigma_{\pi}-p_{\text {int }}\right)$ at any point in the particle is known to be lower than Young's modulus of the particle $\left(2.5 \mu_{p}\right)$ for any value of $\lambda_{a}$ inside the void [8]. In a real rubber material, $\sigma_{\mathrm{rr}}$ can nevertheless be higher when $\lambda_{\mathrm{a}}$ reaches its limiting value for the rubber under bi-axial tension and other terms are then required to describe the energy density function of the material [11]. However, it will be further shown that the fracture can occur before reaching the limiting stretch within the void. The shear energy $\mathrm{U}_{2}^{\gamma}$ and the hydrostatic energy $\mathrm{U}_{2}^{\mathrm{h}}$ are given by:

$$
\begin{gathered}
U_{2}^{\gamma}=2 \pi \mu_{\mathrm{p}}\left[\mathrm{b}_{\mathrm{o}}{ }^{3}\left(2 \mathrm{~A}^{\frac{2}{3}}-\mathrm{A}^{\frac{-1}{3}}-1\right)-\mathrm{a}_{\mathrm{o}}{ }^{3}\left(2 \lambda_{\mathrm{a}}{ }^{2}-\lambda_{\mathrm{a}}{ }^{-1}-1\right)\right] \\
\mathrm{U}_{2}^{\mathrm{h}}=\frac{\pi \mu_{\mathrm{p}}{ }^{2}}{3 \mathrm{k}_{\mathrm{p}}}\left\{\mathrm{b}_{\mathrm{o}}{ }^{3}\left[\frac{\mathrm{C}^{2}}{2}+\frac{1}{30}\left(400 \mathrm{~A}^{\frac{1}{3}}-80 \mathrm{~A}^{\frac{4}{3}}+56 \mathrm{~A}^{\frac{-2}{3}}-\mathrm{A}^{\frac{-5}{3}}\right)+\mathrm{C}\left(4 \mathrm{~A}^{\frac{2}{3}}+\mathrm{A}^{\frac{-1}{3}}\right)\right]-\mathrm{a}_{\mathrm{o}}{ }^{3} \mathrm{D}\right\}
\end{gathered}
$$

where $C=\frac{2 p_{\text {int }}}{\mu_{\mathrm{p}}}-4 \lambda_{\mathrm{a}}{ }^{-1}-\lambda_{\mathrm{a}}{ }^{-4}$ and $\mathrm{D}=\frac{\mathrm{C}^{2}}{2}+\frac{1}{30}\left(400 \lambda_{\mathrm{a}}-80 \lambda_{\mathrm{a}}{ }^{4}+56 \lambda_{\mathrm{a}}{ }^{-2}-\lambda_{\mathrm{a}}{ }^{-5}\right)+\mathrm{C}\left(4 \lambda_{\mathrm{a}}{ }^{2}+\lambda_{\mathrm{a}}{ }^{-1}\right)$

In previous papers $[2,4], U_{2}^{\gamma}$ and $U_{2}^{\text {h }}$ are neglected. Although this is usually a reasonable assumption for polymeric materials (Fig. 5), in the case of rubber-like elasticity where the radial pressure $\sigma_{\mathrm{rr}}$ cannot exceed an asymptotic value $\sigma_{\mathrm{rr} \text { asympt }}=\mathrm{p}_{\mathrm{int}}+2.5 \mu_{\mathrm{p}}$, if $\mathrm{p}_{\mathrm{h}}>\mathrm{p}_{\text {int }}+2.5 \mu_{\mathrm{p}}$, the appearance of a void leads to a sudden fall in pressure at the interface.

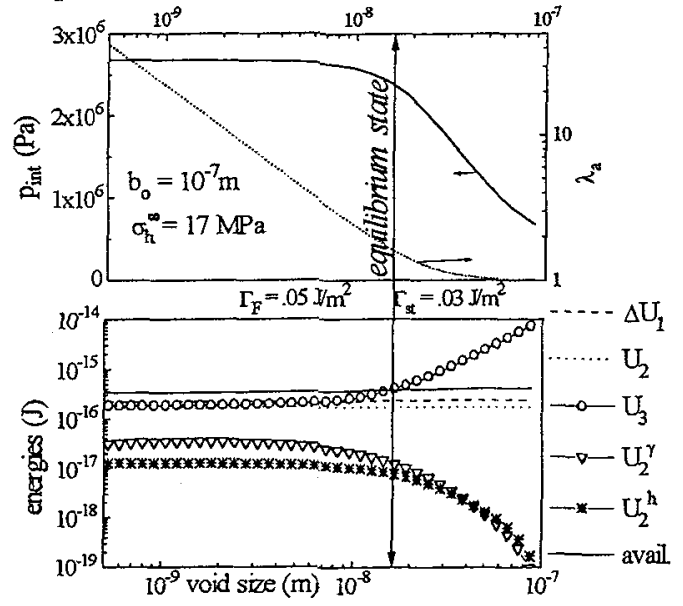

Fig. 5. Energies involved in the energy balance for fracture with respect to volume change (the available energy is $\Delta U_{1}+U_{2}-U_{2}^{\gamma}$ $\left.-U_{2}^{h}\right)$.

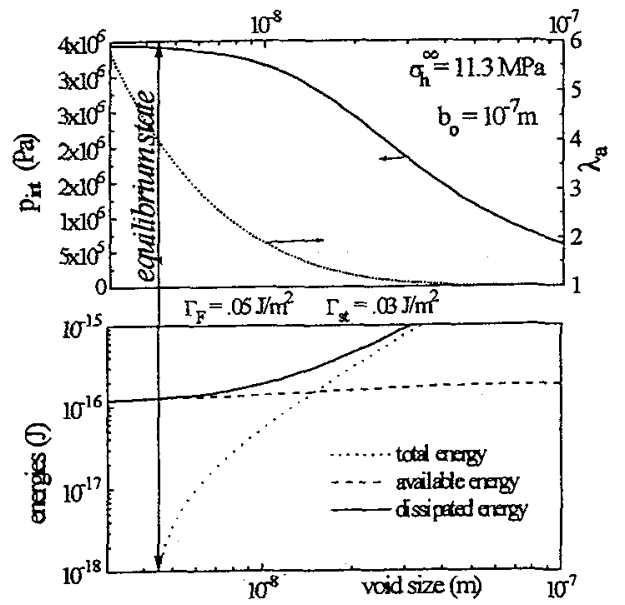

Fig. 6. Energies, internal pressure due to surface tension and internal void extension ratio for the limit load which could energetically create a void. 


\section{3. Energy balance}

Driving forces for void growth originate from the mechanically released stored potential energy and the work done by external forces before and after enlargement of the void. The component $U_{1}$ of this energy outside the particle before cracking is obtained from eq. (2):

$$
\Delta \mathrm{U}_{1}=\frac{\mathrm{V}_{\mathrm{p}}}{2} \frac{3\left(1+v_{\mathrm{m}}\right)\left(\mathrm{p}_{\mathrm{h}}^{2}-\sigma_{\mathrm{rr}}^{2}\right)}{2 \mathrm{E}_{\mathrm{m}}}
$$

where $p_{h}$ is given by eq. (4) and $\sigma_{\pi}$ is the radial pressure at the interface $\left(\rho=b_{0}\right)$ given by eq. (11). In order to take into account the sudden pressure drop at the interface when a void appears, the energy balance is written as the total energy before and after void formation. The asymptotic value of $\sigma_{\mathrm{rr}}$ is [8]:

$$
\sigma_{\text {Ir asympt }}=\frac{2 \Gamma_{\mathrm{st}}}{\mathrm{a}}+\frac{\mu_{\mathrm{p}}}{2}\left(5-4 \lambda_{\mathrm{a}}^{-1}-\lambda_{\mathrm{a}}^{-4}\right)<\mathrm{p}_{\text {int }}+\frac{5 \mu_{\mathrm{p}}}{2}
$$

The hydrostatic pressure $p_{h}$ (proportional to the external load) is generally greater than $\sigma_{\pi}$ asympt before the development of voids. As the external load increases, voids can appear when:

$$
\Delta \mathrm{U}_{1}+\left(\mathrm{U}_{2}-\mathrm{U}_{2}^{\mathrm{h}}-\mathrm{U}_{2}^{\gamma}\right)-\mathrm{U}_{3} \geq 0
$$

Calculation of $\lambda_{\mathrm{a}}$ and $\mathrm{a}_{0}$ is then possible using this condition and eq. (10). A further increase in crack surface is obtained for:

$$
\frac{\partial U_{1}}{\partial \sigma_{\mathrm{rr}}} \frac{\partial \sigma_{\mathrm{rr}}}{\partial \mathrm{a}_{\mathrm{o}}}+\frac{\partial \mathrm{U}_{2}}{\partial \mathrm{a}_{\mathrm{o}}}+\frac{\partial \mathrm{U}_{3}}{\partial \mathrm{a}_{\mathrm{o}}} \leq 0
$$

where $U_{1}$ is the sum of the recoverable energy of the matrix and the work done by external forces and $U_{2}$ the recoverable energy of the particle. The first of these parameters can be derived from eq. (2), the second from eq. (12) and the third from eq. (8). Since $U_{2}$ contains an important hydrostatic strain energy only before void formation $\left(\frac{\partial \mathrm{U}_{2}}{\partial \mathrm{a}_{\mathrm{o}}} \approx 0\right.$ after the void formation), the external load must increase significantly to further increase the crack surface once the void has been created.

\section{4. Application to rubber toughened PMMA}

The use of the above equations is made to estimate the load under which no damage occurs in the particle. The problem is to find, for a given load $\sigma_{h}^{\infty}$, the physically admissible values of void radius $a_{0}$ and extension ratio $\lambda_{\mathrm{a}}$. These must satisfy the compatibility in volume and stresses between the matrix and the particle and energy conservation. A dichotomy has been used to compute the values. When no solution is found, $\sigma_{h}^{\infty}$ is increased since the stored energy suffices to create a fracture surface $\left(a_{0}\right)$ large enough to obtain an extension ratio $\lambda_{\mathrm{a}}$ less than 5 which is considered as the maximum extension ratio of the rubber material.

Table 1: Mechanical properties of PMMA used in numerical calculations.

\begin{tabular}{|l|l|}
\hline Matrix: & Rubber particle: \\
\hline$\left\{\begin{array}{c}\mathrm{E}_{\mathrm{m}}=310^{9} \mathrm{~Pa} \\
v_{\mathrm{m}}=0.4\end{array} \Leftrightarrow\left\{\begin{array}{c}\mathrm{k}_{\mathrm{m}}=510^{9} \mathrm{~Pa} \\
\mu_{\mathrm{m}}=1.0710^{9} \mathrm{~Pa}\end{array}\right.\right.$ & $\left\{\begin{array}{c}\mathrm{E}_{\mathrm{p}}=110^{6} \mathrm{~Pa} \\
v_{\mathrm{p}}=0.4999167 \\
\Gamma_{\mathrm{st}}=0.03 \mathrm{~J} / \mathrm{m}^{2}\end{array}\right.$
\end{tabular}$\Leftrightarrow\left\{\begin{array}{c}\mathrm{k}_{\mathrm{p}}=210^{9} \mathrm{~Pa} \\
\mu_{\mathrm{p}}=3.3310^{5} \mathrm{~Pa}\end{array}\right.$

For the mechanical properties of polymethylmethacrylate (PMMA) given in Table 1 and a particle diameter of $200 \mathrm{~nm}$, fig. 6 shows that voids cannot form when the hydrostatic component of the load is less than 11 $\mathrm{MPa}$, since the internal pressure $\mathrm{p}_{\text {int }}$ due to surface tension recloses any initiating void. Moreover, the extension ratio $\lambda_{\mathrm{a}}$ would be more than 10 at the equilibrium state, which is physically meaningless. The results of fig. 7 indicate that the limit load for a void to appear decreases rapidly as the particle size increases. For all these values $\lambda_{\mathrm{a}}$ never exceeds 3.3 . It is clear that for large particles the above criteria does not suffice to predict the void formation (see section 4).

At a molecular level, the microscopic fracture energy $\Gamma_{\mathrm{F}}$ is lower than the macroscopic energy: the smaller the crack surface, the smaller the volume of material highly stretched around the crack tip, the smaller the 
energy dissipated around the crack tip, the smaller the fracture energy. The energy employed for molecular debonding is comparable to the surface energy [4]. Indeed, for a macroscopic fracture energy (typically 50 $\mathrm{J} / \mathrm{m}^{2}$ ), the void size created by fracture would be physically meaningless for particles with a radius of less than a few microns. Although for very low levels of fracture energy, the surface tension $\Gamma_{\text {st }}$ in eq. (8) is not negligible, the most important effect of this surface tension is the significant value of the internal pressure pint which induces a residual stretch in very small voids. In order to analyse the effect of the surface tension, the load $\sigma_{\mathrm{h}}^{\infty}$ corresponding to the void formation is arbitrarily fixed at $17 \mathrm{MPa}$, which corresponds to the yield stress of the blend at room temperarure and moderate extension rate. Calculations taking into account or not the surface tension are compared in Fig. 8. As expected, this tension becomes negligible when the void size is larger than $20 \mathrm{~nm}$ (the particle size greater than $0.1 \mu \mathrm{m}$ ).

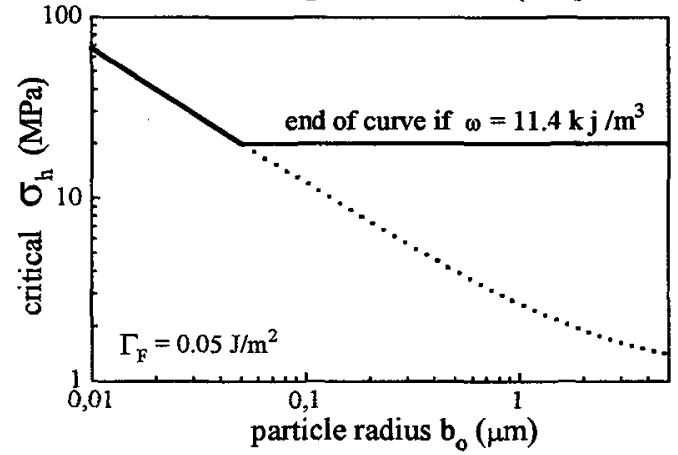

Fig. 7. Critical hydrostatic stress for a void formation if the energy density corresponding to the energy barrier is $11.4 .9 \mathrm{kj} / \mathrm{m}^{3}$ (change of slope for $b_{o}=50 \mathrm{~nm}$ ).

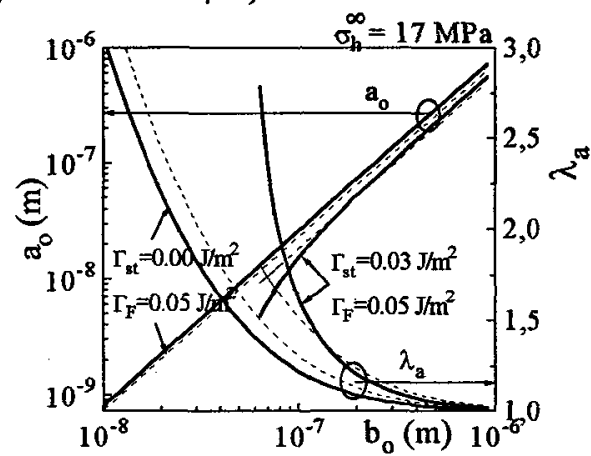

Fig. 8. Comparison between results taking into account or not the surface tension $\Gamma_{\mathrm{ST}}$ (dashed curves for the simplified model of eq. (21)).

\section{ENERGY BARRIER FOR VOID FORMATION}

Energy conservation predicts that the external load $\sigma_{h}^{\infty}$ necessary to create a void in a particle decreases as the particle size $b_{\circ}$ increases, which means that large particles would be expected to be very brittle (dashed curve of Fig. 7). Indeed, a load $\sigma_{\mathrm{h}}^{\infty}$ of $1.2 \mathrm{MPa}$ would be large enough to create a void of $50 \mu \mathrm{m}$ in a 100 $\mu \mathrm{m}$ particle (with $\Gamma_{\mathrm{F}}$ equal to its microscopic value of $50 \mathrm{~mJ} / \mathrm{m}^{2}$, as discussed below). The real behaviour is different because the initiation of a void cannot be considered from a static and macroscopic point of view. At first glance, the condition for growth of an initial void of radius $a_{0}$ is that the internal load due to surface tension must be lower than the external pressure applied by the matrix on the particle:

$$
p_{\text {ext }}>p_{\text {int }} \text { with } p_{\text {int }}=\frac{2 \Gamma_{\text {st }}}{a_{0}} \text { and } p_{\text {ext }}=p_{h}=A \sigma_{h}^{\infty} \Rightarrow a_{0}>\frac{2 \Gamma_{\text {st }}}{A \sigma_{h}^{\infty}}
$$

where $A=\frac{\left(1-v_{m}\right)}{\left(1+v_{m}\right)} \frac{9 k_{p}}{4 \mu_{m}+3 k_{p}}$. The energy density $\omega$ required to create this void is then:

$$
\omega=\frac{4 \pi \Gamma_{\mathrm{st}} \mathrm{a}_{\mathrm{o}}^{2}}{\mathrm{~V}_{\mathrm{pi}}}=\frac{12}{\mathrm{~A}^{2}} \frac{\Gamma_{\mathrm{st}}{ }^{3}}{\mathrm{~b}_{\mathrm{o}}{ }^{3} \sigma_{\mathrm{h}}^{{ }^{\infty}}}
$$

Using the mechanical properties of Table $1, A$ is calculated to be equal to $3 / 4$. The Fig. 7 is plotted for $\Gamma_{\mathrm{F}}=50 \mathrm{~mJ} / \mathrm{m}^{2}$. If the rubber material behaviour is such that the initiation of the void needs an energy density of $11.4 \mathrm{kj} / \mathrm{m}^{3}$, which corresponds to a hydrostatic tension of $6.8 \mathrm{MPa}$, then the curve critical $\sigma_{\mathrm{h}}^{\infty}$ vs. $b_{o}$ changes of slope for $b_{o}=50 \mathrm{~nm}$. This indicates that for particles larger than $50 \mathrm{~nm}$, even if the stored energy suffices to damage the particle, damage occurs only if the energy density in the particle reaches its 
initiation value. Therefore, except for very small particles, $\omega$ and so the critical $\sigma_{h}^{\infty}$ are expected to be independent of the particle size.

\section{SIMPLIFIED MODEL}

For a polymeric material, since $p_{i n t}$ is low (particle radius of $100 \mathrm{~nm}$ or more), the stretched void size is nearly constant since the volume change involves first a non damaged particle and then a hole in a matrix (Fig. 9).

This is an effect of the very low residual pressure in the particle after cracking and will enable further simplification as $\mathrm{U}_{2}^{\gamma}$ is also very low (Fig. 5). Since the radial pressure $\sigma_{\mathrm{rr}}$ is generally negligible when a cavity exists in the particle, the energy released in the matrix is that of a cavity in an infinite matrix. The material constituting the particle can now be considered incompressible as it is under no significant hydrostatic pressure. Thus the volume change of the particle must be equal to the volume change of the hole in the matrix (Fig. 10):

$$
\sigma_{\mathrm{rr}} \approx 0 \Rightarrow \frac{\Delta V}{V}=\frac{9 \sigma_{\mathrm{h}}^{\infty}\left(1-v_{\mathrm{m}}\right)}{2 \mathrm{E}_{\mathrm{m}}} \approx \frac{\mathrm{b}^{3}}{\mathrm{~b}_{\mathrm{o}}^{3}}-1
$$

and the condition of incompressibility leads to:

$$
b^{3}-\left(\lambda_{a} a_{0}\right)^{3}=b_{0}{ }^{3}-a_{0}{ }^{3}
$$

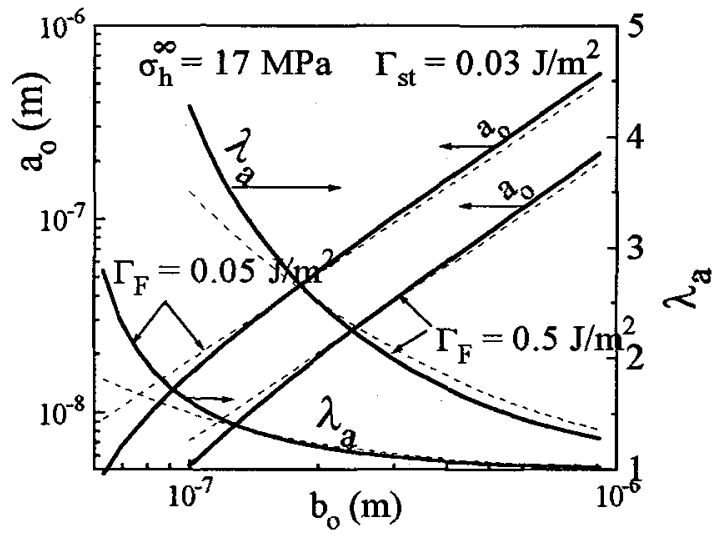

Fig. 9. Void size and internal extension ratio for a void appearing at a hydrostatic load of $17 \mathrm{MPa}$ (dashed curves for the simplified model of eq. (21)).

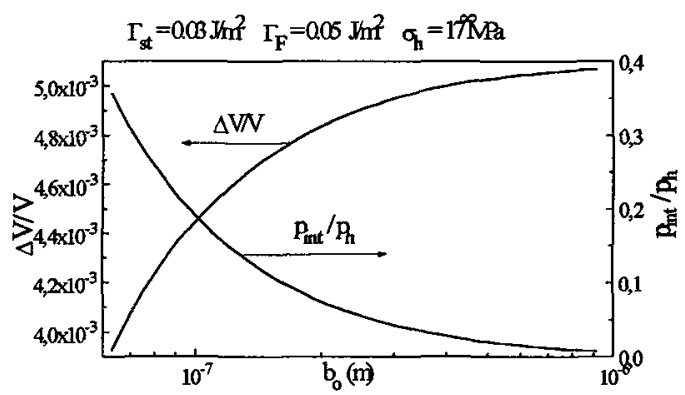

Fig. 10. Volume changes and internal pressure due to surface tension after void formation at $\sigma_{\mathrm{h}}^{\infty}=17 \mathrm{MPa}$.

As $k_{\mathrm{p}} \approx 2 \mathrm{E}_{\mathrm{m}} / 3\left(1+v_{\mathrm{m}}\right)$ and $U_{2}^{\gamma} \approx U_{2}^{h} \approx 0$, the energy available to create a surface $\left(\Delta U_{1}+U_{2}\right)$ is thus given by:

$$
\Delta \mathrm{U}_{1} \approx \mathrm{U}_{2} \approx \frac{1}{2} \frac{\mathrm{p}_{\mathrm{h}}{ }^{2}}{\mathrm{k}_{\mathrm{p}}} \frac{4 \pi \mathrm{b}_{0}^{3}}{3} \quad \text { with } \quad \mathrm{p}_{\mathrm{h}}=\mathrm{A} \sigma_{\mathrm{h}}^{\infty}
$$

where $A=\frac{\left(1-v_{m}\right)}{\left(1+v_{m}\right)} \frac{9 k_{p}}{4 \mu_{m}+3 k_{p}}$. Combining eq. (19) and eq. (20) and using $U_{3} \approx 4 \pi a_{o}\left(\Gamma_{F}+\Gamma_{s t}\right)$, the void size is:

$$
a_{0} \approx 0.6 p_{h} \sqrt[2]{\frac{b_{0}{ }^{3}}{k_{p}\left(\Gamma_{F}+\Gamma_{s t}\right)}} \quad \text { and } \quad \lambda_{a} \approx \sqrt[3]{1+\frac{\Delta V}{V}\left(\frac{b_{0}}{a_{0}}\right)^{3}}
$$

The results of these approximations are presented in Fig. 9 and 8 (dashed curves).

The calculation of the critical hydrostatic stress leading to a cavity formation may also simplified if $\sigma_{\mathrm{h}}^{\infty}>10 \mu_{\mathrm{p}}, \mathrm{U}_{2}^{\gamma} \ll \mathrm{U}_{2}$. Then the energy conservation can be approximated by: 
$\frac{4 \pi b_{0}^{3}\left(p_{h}^{2}-p_{\text {int }}^{2}\right)}{3 k_{p}}=4 \pi a_{0}^{2}\left(\Gamma_{F}+\lambda_{a}^{2} \Gamma_{s t}\right) \quad \Leftrightarrow \quad \frac{b_{0}^{3}}{3 k_{p}}\left(A^{2} \sigma_{h}^{\infty 2}-\frac{4 \Gamma_{s t}^{2}}{a_{0}^{2} \lambda_{a}^{2}}\right)=a_{0}^{2}\left(\Gamma_{F}+\lambda_{\mathrm{a}}^{2} \Gamma_{s t}\right)$ Again, if $\lambda_{a} \approx 1$, the minimum hydrostatic stress leading to the equilibrium of the cavity is:

$$
\sigma_{\mathrm{h}}^{\infty}=\frac{2.6}{\mathrm{~A}} \mathrm{~b}_{\mathrm{o}}^{-3 / 4} \mathrm{k}_{\mathrm{p}} \mathrm{p}^{1 / 4} \Gamma_{\mathrm{st}}{ }^{1 / 2}\left(\Gamma_{\mathrm{F}}+\Gamma_{\mathrm{st}}\right)^{1 / 4}
$$

This approximation underestimates $\sigma_{\mathrm{h}}^{\infty}$. For the material define in Table 1 , the error is less than $15 \%$ if $\sigma_{\mathrm{h}}^{\infty}$ $=10 \mu_{\mathrm{p}}$ and less than $5 \%$ if $\sigma_{\mathrm{h}}^{\infty}=20 \mu_{\mathrm{p}}$. It can be shown that the effect of the stresses induced by the differential expansion of the materials due to a temperature change is not significant [9].

\section{ONSET OF PLASTICITY}

The plasticity criterion employed for amorphous polymers is usually a Von Mises type criterion which depends on the hydrostatic stress [2]. Whereas the hydrostatic stress $\sigma_{h}$ around a particle is not influenced by the pressure at the interface (Fig. 11), the Von Mises equivalent stress $\tau_{\mathrm{e}}$ increases when the hydrostatic pressure decreases within the particle. In the case of pure PMMA, the yield stress $\sigma_{y}$ depends on strain rate and temperature. At a strain rate of $10^{-4} \mathrm{~s}^{-1}$, the threshold stress is estimated to be [13]:

$$
\begin{gathered}
\sigma_{\mathrm{y}}(\mathrm{MPa})=\left(1.2 \mathrm{~T}\left({ }^{\circ} \mathrm{C}\right)-132\right) \text { in uniaxial compression } \\
\text { and } \sigma_{\mathrm{y}}(\mathrm{MPa})=\left(100-0.9 \mathrm{~T}\left({ }^{\circ} \mathrm{C}\right)\right) \text { in uniaxial tension }
\end{gathered}
$$

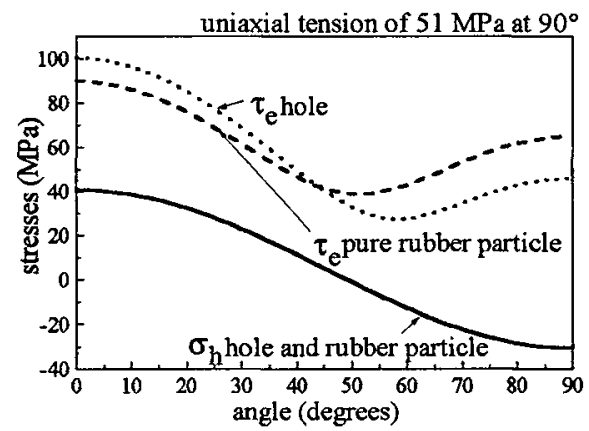

Fig. 11. Von Mises equivalent stress $\tau_{\mathrm{e}}$ and hydrostatic stress concentration around a pure rubber particle and around a cavity in uniaxial tension $(\varepsilon=1.7 \%)$.

The corresponding hydrostatic stresses are respectively $-36 \mathrm{MPa}\left(\sigma_{\mathrm{y}}=-108 \mathrm{MPa}\right)$ and $27 \mathrm{MPa}\left(\sigma_{\mathrm{y}}=82\right.$ $\mathrm{MPa}$ ) at room temperature, while $\tau_{\mathrm{e}}$ is equal to the load $\left(\tau_{\mathrm{e}}=3 \sigma_{\mathrm{h}}^{\infty}\right.$ in uniaxial tension). At the equator of the particle, $\sigma_{\mathrm{h}} / \sigma_{\mathrm{h}}^{\infty}=2.46$ and $\tau_{\mathrm{e}} / \sigma_{\mathrm{h}}^{\infty}=5.34$ before void formation (fig. 11). Since no interaction between particles modifies this stress field, before the appearance of a void, plasticity will be expected to develop at the equator for an external uniaxial load of less than $46 \mathrm{MPa}$. After the appearance of a void, the plasticity will develop for a load of less than $41 \mathrm{MPa}$. Consequently, plasticity can arise with or without cavity formation depending on the strain rate and whether the temperature is low or high and the plasticity at the equator may lead to the initiation of a craze.

\section{DISCUSSION AND CONCLUSION}

Void formation and growth is governed by four conditions:

1 - conservation of energy (Griffith's scheme),

2 - compatibility of the volume change between a particle and its surrounding matrix,

3 - extension inside the void, which must be less than the maximum extension of the rubber under bi-axial tension on a microscopic scale,

4 - size of the stretched void, which must be greater than a minimum size. Thus implies that the internal pressure due to surface tension must be small. The minimum size is not well defined.

The transfer of continuum mechanics from a macroscopic to a microscopic scale requires care. In reality 
the microscopic fracture energies are unknown and cannot be measured and similarly the behaviour of a given material (rubber-like elasticity for instance) near a pre-existing flaw cannot be precisely predicted. However, the present model can be used to obtain an order of magnitude of the microscopic fracture energy. Initiation of a void takes place at a pre-existing flaw or in a region where the molecular bonding is of lower density, the minimum permissible void size usually being of the order of a few nanometers. Such a mechanical model does not include the dynamic contribution from atomic forces which is responsible for the instability of voids less than a few nanometers in size. This contribution is more adequately described by molecular physics than by mechanics. Furthermore, since the microscopic fracture energy involves more volume dissipation as a crack propagates, this term may be expected to increase with the crack surface and hence $\Gamma_{\mathrm{F}}$ cannot be constant. Figures 5, 7, 8, 9 and 10 may thus be different for large particle sizes (i. e. large fracture surfaces).

In summary, when a Griffith's scheme is applied to internal fracture in rubber particles, using Eshelby's results for particles embedded in an elastic matrix, the particle size is predicted to control the polymer behaviour for usual rubber modified PMMA. As the calculations involve a microscopic fracture energy, comparison of the model with experiments is not easy. The minimum size of a stretched void and the energy barrier for its formation are likewise poorly defined and are physical parameters which determine the range of validity of the model for larger particles. Nevertheless, the model predicts that the critical load leading to void formation depends on the particle size for small particles (typically less than $100 \mathrm{~nm}$ ) and. for large particles (typically $1 \mu \mathrm{m}$ ), depends on the energy barrier to initiate the void. This barrier is independent of the particle size.

Interactions between particles are known to be important but are not taken into account. However, the model predicts the yield stress for a matrix containing non interacting particles to be half the stress for a pure PMMA matrix (Fig. 11). If the volume fraction of the particles is $26 \%$, this ratio is 2.3 at room temperature [13], since the stress concentration increases with decreasing the distance between particles.

\section{REFERENCES}

[1] Dijkstra, K., Van Der Wal, A., Gaymans, R. J., Nylon-6-Rubber Blends part IV: Cavitation and Yield in Nylon-Rubber Blends, J. Mat. Sci., 29, (1994), pp. 3489-3496.

[2] Lazzeri, A., Bucknall, C. B., Dilatational Bands in Rubber-Toughened Polymers, J. Mat. Sci., 28, (1993), pp. 6799-6808.

[3] Bucknall, C. B., Karpodinis, A., Zhang, X. C., A Model for Cavitation in Rubber-Toughened Plastics, J. Mat. Sci., 29, (1994), pp. 3377-3383.

[4] Dompas, D., Groeninckx, G., Toughening behaviour of rubber-modified thermoplastic polymers involving very small rubber particles: 1. A criterion for internal rubber cavitation, Pol. 35, (1994), pp. 4743-4749.

[5] Eshelby, J. D., The Determination of the Elastic field of an Ellipsoidal Inclusion, and Related Problems, Proc. Roy. Soc. Lond. A, 241, (1957), pp. 376-396.

[6] Eshelby, J. D., The Elastic Field Outside an Ellipsoidal Inclusion, Proc. Roy. Soc. Lond. A, 252, (1959), pp. 561-569.

[7] Goodier, J. N., Concentration of Stress Around Spherical and Cylindrical Inclusions and Flaws, A.S.M.E. Trans., 55, (1955).

[8] Green, A. E., Zerna, W., Theoretical Elasticity, (1954), University Press, Oxford.

[9] Fond, C, Lobbrecht, A., Schirrer, Polymers Toughened with Rubber Microspheres: an Analytical Solution for Stresses and Strains in the Rubber Particles at Equilibrium and Rupture, Int. J. Frac., to be published.

[10] Mauzac, O., Schirrer, R., Crack tip damage zone in rubber toughened amorphous polymers: a micromechanical model, J. Mat. Sci. 25, (1992), pp. 5125-5133.

[11] Gent, A. N., Lindley, P. B., Internal Rupture of Bonded Rubber Cylinders in Tension, Proc. Roy. Soc. Lond. A, 249, (1959), pp. 195-205.

[12] Williams, M. L., Schapery, R. A., Spherical Flaw Instability in Hydrostatic Tension, Int. J. Fract. Mech., 1, (1964).

[13] Bouton Rochelle, C., Etudes des mécanismes de déformation plastique dans des mélanges de Poly(Methacrylate de Methyle), Ph. D. Thesis, (1991). 